\title{
Laboratório de Dramaturgismo e Direção Rotativa de Cenas: encenação em processo colaborativo de criação teatral
}

\author{
"Laboratório de Dramaturgismo e Direção Rotativa de Cenas": la puesta
}

en escena em um proceso de creación colaborativa em teatro

"Laboratório de Dramaturgismo e Direção Rotativa de Cenas": the

direction of scenes in a collaborative process of theater creation

\author{
Ma. Maria Amélia Gimmler Netto ${ }^{1}$ \\ Dra. Fernanda Vieira Fernandes ${ }^{2}$
}

\begin{abstract}
Resumo
Este artigo apresenta as bases de uma pesquisa que visa desenvolver possibilidades metodológicas para a pedagogia da cena contemporânea. Realizar prática teatral, através de laboratório de composição, para investigar possibilidades de criação em grupo, a partir da prática da direção rotativa de cenas é o principal objetivo da pesquisa, ainda em andamento. O estudo teórico das características da cena contemporânea, aliado à prática de composição em laboratório, permitirá definir aspectos da postura do professor de teatro que atua enquanto encenador e condutor de um processo colaborativo de criação. O Laboratório de Dramaturgismo e Direção Rotativa é conduzido por duas professoras do Curso de Teatro-Licenciatura da Universidade Federal de Pelotas UFPel, cada uma com um enfoque de pesquisa distinto, porém complementares na prática artística em questão. Sendo que uma pesquisa tem foco em questões que envolvem a dramaturgia e a outra tem foco nas questões da encenação, especificamente, a partir do projeto de Pesquisa intitulado Composição de cenas e condução de grupo em processo colaborativo de criação teatral no "laboratório de dramaturgismo e diração rotativa de cenas. Para apresentar elementos conceituais e artísticos da referida pesquisa em andamento a autora abordará também o estudo e a prática realizados no projeto Jogatina: jogo de aprendizagem, teatro pós-dramático e suas contribuições para a pedagogia do teatro, que antecedeu à investigação em questão. A ideia de Direção Rotativa de Cenas em um Processo Colaborativo de Criação em Teatro e seu desenvolvimento é o que norteia a pesquisa em andamento aqui apresentada.
\end{abstract}

Palavras-Chave: Processo Colaborativo de Criação; Direção Rotativa de Cenas; Pesquisa em Artes Cênicas; Pedagogia da Cena Contemporânea.

\section{Resumen}

Se presentan en este articulo las bases de una investigación que tiene como objetivo desarrollar las posibilidades metodológicas para la pedagogía de la escena contemporânea. La realización de práctica teatral por medio de laboratorio de criación, para investigar las posibilidades de creación en grupo, a partir de la práctica de la "Puesta en Escena por Posto Rotativo" es el objetivo principal de la investigación en curso. El

\footnotetext{
${ }^{1}$ Mestre em Artes Cênicas; Programa de Pós-graduação em Artes Cênicas - UFRGS; Porto Alegre, Rio Grande do Sul, Brasil; Docente do Curso de Teatro-Licenciatura - UFPel; Pelotas, Rio Grande do Sul, Brasil; mamelianetto@gmail.com
}

2 Doutora em Letras; Programa de Pós-graduação em Letras - UFRGS; Porto Alegre, Rio Grande do Sul, Brasil; Docente do Curso de Teatro-Licenciatura - UFPel; Pelotas, Rio Grande do Sul, Brasil; nvnandes@ gmail.com 

e-ISSN 2016/Atual: 2525-7870 | e-ISSN 2015/2016: 2447-018X

estudio teórico de las características de la escena contemporánea, combinado con la práctica de la composición en el laboratorio, definirá los aspectos de la postura del profesor de teatro que actúa como director y conductor de un proceso de creación colaborativa. El Laboratorio de Dramaturgismo e Direção Rotativa de Cenas és coordinado por duas maestras del Curso de Teatro de la Universidade Federal de Pelotas - UFPel, cada una con un enfoque de investigación distinto pero que complementares en la práctica artística en cuestión. Dado que uma de las investigaciones se ha centrado en cuestiones relacionadas con la dramaturgia y la otra se centra en las questiones de la puesta en escena, a saber, el proyecto de investigación titulado Composição de cenas e condução de grupo em processo colaborativo de criação teatral no "laboratório de dramaturgismo e diração rotativa de cenas. Además de presentar los elementos conceptuales y artísticos de la investigación en curso, también abordase aqui el estudio y la práctica llevada a cabo en el proyecto de investigación Jogatina: jogo de aprendizagem, teatro pós-dramático e suas contribuições para a pedagogia do teatro que precedió a la investigación en cuestión. La idea de puesta en escena por posto rotativo entre los miembros del equipo, en un proceso de creación colaborativa en teatro y su desarrollo está guiando la investigación en curso que es aqui presentada.

Palabras claves: Proceso de Creación Colaborativa; Puesta en Escena por Posto Rotativo; Investigación en Artes escénicas; Pedagogía de la Escena Contemporánea.

\section{Abstract}

This article presents the basis of a research that aims to develop methodological possibilities for the pedagogy of the contemporary scene. Performing theatrical practice, through a composition laboratory, to investigate possibilities of group creation, from the practice of rotating staging of theater scenes is the main objective of the research, still in progress. The theoretical study of the characteristics of the contemporary scene, together with the practice of composition in the laboratory, will define aspects of the posture of the theater teacher who acts as director and conductor of a collaborative process of creation. The Laboratório de Dramaturgismo e Direcão Rotativa de Cenas is conducted by two professors of the Theater Course of the Universidade Federal de Pelotas - UFPel, each with a distinct research focus, but complementary in the artistic practice in question. One research focus is the involving dramaturgy and the other focus is the staging, specifically, from the research project entitled Composição de cenas e condução de grupo em processo colaborativo de criação teatral no Laboratório de Dramaturgismo e Direção Rotativa de Cenas". To present conceptual and artistic elements of this research, the author will also address the study and practice carried out in the previously research project Jogatina: jogo de aprendizagem, teatro pós-dramático e suas contribuições para a pedagogia do teatro. The idea of rotating staging of theater scenes in a collaborative process of creation in theater and its development is what guides the ongoing research presented here.

Keywords: Collaborative Process of Creation; Rotating Direction of Scenes; Research in Performing Arts; Pedagogy of the Contemporary Scene.

\section{Introdução}

Este trabalho apresenta as bases de uma proposta de pesquisa que visa desenvolver possibilidade metodológica para a pedagogia da cena contemporânea. Realizar prática teatral, através de laboratório de composição, para investigar possibilidades de criação em grupo, a partir da prática da direção rotativa de cenas é o principal objetivo da pesquisa, ainda em andamento. $\mathrm{O}$ estudo teórico das características da cena contemporânea, aliado à prática de composição em laboratório, permite definir aspectos da postura do professor de teatro que atua enquanto encenador e condutor de um processo colaborativo de criação.

\section{O Laboratório de Dramaturgismo e Direção Rotativa de cenas é conduzido pelas} professoras da UFPel Maria Amélia Gimmler Netto e Fernanda Vieira Fernandes, cada uma com um enfoque de pesquisa distinto, porém complementares entre si na prática de laboratório. A equipe é formada por quatro estudantes do Curso de Teatro-Licenciatura da 
UFPel, Juliana Caroline da Silva, Johann Ossanes, Marco Antonio Duarte e Mario Celso Pereira Junior e por três estudantes egressos do Curso, Lucas Galho, Gabrielle Winck e Tatiana Duarte. Também colaboraram no processo Gab Mesquita e Fernanda Miki, nos arranjos e preparação musical para percussão e canto, respectivamente.

A pesquisa em andamento aqui abordada tem enfoque na encenação, intitula-se Composição de cenas e condução de grupo em processo colaborativo de criação teatral no "laboratório de dramaturgismo e direção rotativa de cenas" e é vinculada ao Grupo de Estudos e Pesquisas em Teatro, Educação e Práxis Social da Pró-Reitoria de Pesquisa e PósGraduação da UFPel.

2.Estudo e prática antecedentes à pesquisa em questão: Jogatina: jogo de aprendizagem, teatro pós-dramático e suas contribuições para a pedagogia do teatro

A pesquisa em questão surgiu como possibilidade de desdobramento e aprofundamento de uma investigação que foi realizada na Universidade Federal de Pelotas UFPel por equipe composta por professora e estudantes do Curso de Teatro-Licenciatura, entre setembro de 2013 e dezembro de 2015. Jogatina: jogo de aprendizagem, teatro pósdramático e suas contribuições para a pedagogia do teatro foi um projeto de pesquisa teórico-prático no campo teatral que teve como ponto de partida a seguinte questão: Quais as atuais possibilidades educativas para o teatro contemporâneo que podem ser descobertas a partir do estudo e da prática das peças didáticas de Bertolt Brecht? Sendo assim, o estudo buscou articular conhecimentos teatrais acerca das peças didáticas de Bertolt Brecht, escritas na década de 1930 com o conceito de teatro pós-dramático proposto por Hans-Thies Lehmann, a partir da década de 1990.

Como resultado da pesquisa supracitada constatou-se o enriquecimento da experiência poética dos estudantes, através do jogo criativo com as peças didáticas, da criação de depoimentos pessoais que contemplam suas inquietudes públicas e privadas e do aprendizado de um modo de compor cenas em grupo, a partir da prática da direção rotativa de cenas entre os membros da equipe. Identificou-se também uma forma de treinamento de elenco que se desenvolveu ao longo da prática de laboratório criativo e culminou com a finalização de um exercício cênico que foi apresentado ao público formado por jovens estudantes do Ensino Médio, universitários, professores e espectadores interessados. Esta obra, que intitulou-se Jogatina, teve a direção da professora Maria Amélia Netto, o elenco foi formado por Francesco d'Avila, Arthur Malaspina, Ryan Hafid, Luana Franz, Anderson 
Morais, Lucas Galho e Monique Carvalho e sua estreia foi em julho de 2014 na cidade de Pelotas/RS.

O estudo de ambos os conceitos elegidos, sendo eles o Jogo de Aprendizagem e o Teatro Pós-Dramático, aliado à vivência de experiências de criação cênica proporcionaram aos participantes de Jogatina um maior conhecimento da linguagem teatral e também a ampliação de suas capacidades de criação poética, de seu senso estético, bem como das suas habilidades para refletir sobre as relações entre sujeitos e a formação de coletivos criativos. A crítica social e os debates sobre a situação social e econômica do Brasil atual perpassaram o laboratório criativo realizado nos espaços da Universidade, bem como estiveram presentes também nas ações realizadas com os jovens nas escolas de Ensino Médio que assistiram o resultado cênico da pesquisa em sala de aula.

$\mathrm{O}$ efeito formativo deste estudo na trajetória acadêmica dos estudantes pesquisadores foi percebido igualmente na prática da disciplina Estágio III - Teatro na Comunidade, a partir do projeto Jogatina:Modos de Compor realizado pela dupla de estudantes Arthur Malaspina e Francesco D'Avila, bem como no Trabalho de Conclusão de Curso - TCC A Experiência Estética na JOGATINA: Repercussões na Educação de Jovens Espectadores de Teatro, realizado pelo estudante Anderson Moraes Demutti. Ambos trabalhos foram realizados e concluídos no ano de 2015.

Apesar dos avanços conquistados durante o período de realização do projeto Jogatina, algumas indagações a respeito da formação de professores e da pedagogia da cena contemporânea seguem passíveis de reflexão: Como possibilitar não só o acesso, mas a compreensão e a familiaridade com práticas e teorias teatrais da atualidade, por parte dos jovens aprendizes? Como trabalhar as questões da cena contemporânea na prática teatral com jovens e adultos, tornando-as assimiláveis e prazerosas aos estudantes? Como abordar artisticamente questões sociais complexas sobre nosso tempo, nossa sociedade em um processo de criação de cenas com grupo de jovens?

É a partir dos resultados cênicos obtidos com a pesquisa Jogatina: jogo de aprendizagem, teatro pós-dramático e suas contribuições para a pedagogia do teatro, sobretudo no que se refere ao modo de compor cenas em grupo, que surgiu a necessidade da investigação atual que é aqui relatada. 
RELACult - Revista Latino-Americana de Estudos em Cultura e Sociedade

Revista Latinoamericana de Estudios en Cultura y Sociedad | Latin American Journal of Studies in Culture and Society

V. 03, ed. especial, ago., 2017, p. 20-28 | relacult.claec.org e-ISSN 2016/Atual: 2525-7870 | e-ISSN 2015/2016: 2447-018X

3. Delineamento da Pesquisa: Composição de cenas e condução de grupo em processo colaborativo de criação teatral no "laboratório de dramaturgismo e direção rotativa de cenas”

A pesquisa tem como tema central o estudo teórico e prático da encenação contemporânea e os seus possíveis desdobramentos para o aprimoramento do trabalho do professor de teatro, que se propõe a conduzir processos de composição de cenas em grupo. Trata-se de uma ideia de investigação que alia a prática de laboratório ao estudo teórico para melhor compreender o trabalho do professor de teatro como artista criador e agente fomentador de opinião crítica e de debate social, seja no contexto da docência universitária, do magistério no Ensino Médio, ou ainda, em contextos comunitários. Assim busca-se refletir sobre a presença das práticas teatrais contemporâneas em nossa sociedade relacionando-as ao contexto político e social de nossa época. Ação que se dá como uma forma de aprofundar a prática artístico-pedagógica do professor de teatro realizada em conjunto com jovens e/ou adultos nos âmbitos formais e não formais de ensino.

A questão inicial que guia a pesquisa é: A partir de uma prática de criação teatral e da compreensão de conceitos como processo colaborativo, encenação teatral e jogo de aprendizagem, que metodologia de trabalho pode ser criada para o trabalho do mestreencenador (ou diretor-pedagogo) a partir da experiência do Laboratório de Dramaturgismo e Direção Rotativa de cenas?

São objetivos da pesquisa: Realizar prática teatral, através de laboratório de composição; Estudar as características da cena contemporânea; Desenvolver práticas de composição de cenas em laboratório; Desenvolver uma possibilidade metodológica para a pedagogia da cena contemporânea; Investigar possibilidades de compor cenas em grupo, a partir da prática da direção rotativa de cenas; Definir aspectos da postura do professor de teatro que atua enquanto condutor de um processo criativo em grupos, formados por jovens e/ou adultos; Ampliar os estudos acerca dos rumos da pedagogia do teatro na atualidade, com foco na ideia da encenação contemporânea como prática pedagógica; Refletir sobre a presença das práticas teatrais contemporâneas em nossa sociedade relacionando-as ao contexto político e social de nossa época; Praticar proposta criação de cenas por todos participantes da equipe a partir de texto dramático ou ainda, textos que venham a ser escritos pelos artistas participantes da equipe, em forma de depoimentos pessoais.

Em relação aos aspectos metodológicos da pesquisa estão previstas quatro etapas principais para a investigação, sendo elas: 1) A prática de laboratório de criação e seus procedimentos; 2) A apresentação, circulação e contextualização do experimento cênico em 
festivais ou eventos Universitários, teatros locais e regionais e escolas ou comunidades; 3) Estudo teórico: Revisão de literatura e aprofundamento da compreensão dos conceitos de Processo Colaborativo de Criação, de Criação Coletiva, Encenação Contemporânea, Direção Teatral, Teatro de Grupo e Pedagogia da Cena Contemporânea.

\section{Alguns resultados alcançados com a pesquisa em andamento}

A prática de laboratório de criação foi realizada durante o ano de 2016 e um de seus procedimentos foi testar as possibilidades de uma metodologia de criação de cenas. A partir de um desdobramento da noção de jogo de aprendizagem, proposto por Brecht, a metodologia em questão é a prática da Direção Rotativa de Cenas feita por meio da rotação de proposição de cenas entre os integrantes da equipe, a partir de um mesmo texto como estímulo. O texto dramático definido a partir da proposta da dramaturgista do processo foi "Combate de Negro e de Cães" do dramaturgo francês B.M. Koltès. Nesta etapa buscou-se, também, desenvolver com os participantes uma prática de criação de textos, em forma de depoimento pessoal ou manifesto de artista, para que estes fossem jogados em cena da mesma forma com que se experimentou o jogo com o texto dramático, ou seja, por meio da direção rotativa de cenas como modo de compor. Este manifesto teve como provocação as questões: O quê te trás conforto? E o que te desconforta? Também se utilizou na montagem a referencia de poemas de Angélica Freitas, bem como informações a respeito de situações de opressão social, com foco no machismo e no racismo, retiradas de manchetes jornalísticas e outras fontes de dados estatísticos. Sendo assim, a proposta mesclou métodos de criação coletiva e de processo colaborativo de criação em teatro, incluindo a composição de dramaturgia elaborada por meio do uso de textos dramáticos, não-dramáticos e por depoimentos de autoria dos participantes.

Foram realizados registros áudios-visuais durante a prática de laboratório, bem como na ocasião das apresentações públicas do resultado do processo criativo. Também se realizou registro por escrito das cenas criadas, em forma de roteiro geral de cenas e está em fase de desenvolvimento o registro do experimento em forma de texto dramático.

A apresentação da montagem criada em laboratório foi realizada em espaço da UFPel, em espaço privado destinado à apresentações artísticas e em prédio teatral público. Na ocasião da apresentação de mostra de processo, realizou-se uma versão reduzida da obra que foi chamada de Percurso Combate, estreada em 11 de julho de 2016 no espaço da Fábrica Cultural, em Pelotas, a partir do fomento do Edital Público Municipal "Sete ao Entardecer". Esta apresentação foi precedida de um ensaio aberto para convidados e na ocasião foi desenvolvido um debate entre todos os participantes do experimento. 
A montagem completa do espetáculo Combate: corpos mortos, vivo e por vir teve sua estreia nos dias 15 e 16 de outubro de 2016, no Casarão 8, Museu do Doce da UFPel. Realizou-se, além da curta temporada de estreia, mais uma apresentação no Casarão 8 na ocasião da Semana da Consciência Negra, em novembro de 2016. Neste mesmo mês foi feita apresentação no Teatro Esperança, na cidade de Jaguarão/RS. Para tanto realizou-se adaptação espacial para que a montagem não perdesse sua característica de uso de espaço cênico alternativo, como quando apresentada nas dependências do Casarão 8, edificação colonial do século IX. Para a apresentação de Combate: corpos mortos, vivo e por vir no Teatro Esperança de Jaguarão/RS a equipe não mediu esforços em adaptar a montagem para um espaço teatral, valendo-se do uso do Foyer, dos corredores de plateia, dos balcões do primeiro e segundo andares bem como das escadarias do Teatro e do palco usado também para receber espectadores/as, atores/atrizes, elementos de cenografia e instrumentos musicais.

A parte prática da pesquisa, em laboratório, já está em faze de finalização. A partir da etapa de estreia e adaptação para outros espaços além do original, inicia-se a etapa de produção de novas apresentações, temporadas e circulação do espetáculo em festivais, como um desdobramento dos resultados obtidos. Porém a parte teórica da pesquisa segue em andamento, embora tenha já alguns resultados alcançados, conforme se desenvolvem os estudos conceituais e a produção escrita dos artistas colaboradores participantes da pesquisa.

Alguns resumos expandidos e artigos já foram produzidos para participação em eventos acadêmicos no ano de 2016, como o V SIGAM - Simpósio Internacional de Gênero, Arte e Memória/UFPel, o VIII SECONEP - Seminário da Consciência Negra de Pelotas/UFPel e o V ENPROCULT- Encontro Nacional de Produção Cultural/UNIPAMPA .

\section{Considerações finais}

O estudo teórico da cena contemporânea é concomitante à prática de laboratório e segue em andamento. Ele se dá pela busca de referenciais teóricos e definições sobre os conceitos de Processo Colaborativo de Criação, Criação Coletiva, Encenação Contemporânea, Direção Teatral, Teatro de Grupo e Pedagogia Teatral. O estudo partiu da definição de conceitos como o Teatro Pós-Dramático proposto por Hans-Thies Lehmann, o Processo Colaborativo discutido por Beàtrice Picon-Vallin, a Cena Contemporânea definida por Patrice Pavis; a Arte da Performance discutida por Roselee Goldberg; os Cenários Liminares apresentados por Ileana Diegues; a noção de Performatividade discutida por Josette Feral. Também publicações de pesquisadores brasileiros são fontes usadas para definir o panorama da cena contemporânea nacional, ao exemplo das investigações de Eleonora Fabião, Sílvia Fernandes, 
Antonio Araújo, Luiz Abreu, André Carreira, Stela Fischer e Adélia Nicolete bem como as publicações especificamente voltadas à pedagogia das artes cênicas como as de Ingrid Koudela, Vicente Concílio e Flávio Desgranges. Os conceitos apresentados aqui dão base à parte teórica da pesquisa que é realizada pelas professoras, estudantes e alunos egressos do Curso de Teatro-Licenciatura da UFPel.

Busca-se assim produzir e refletir sobre a presença das práticas teatrais contemporâneas em nossa sociedade relacionando-as ao contexto político e social de nossa época, como uma forma de aprofundar a prática artístico-pedagógica do professor de teatro realizada em conjunto com jovens artistas recém-formados ou ainda em formação.

\section{Referências}

ABREU, Luis A. Processo Colaborativo: Relato e Reflexões sobre uma Experiência de Criação. Cadernos da ELT, Santo André, n. 2, jun. 2004;

ÁQIS Núcleo de Pesquisas sobre Processos de Criação Artística. Falas sobre o Coletivo: Entrevistas sobre o teatro de grupo. Editora Argus-a Artes y HumanidadesqArts and UHumanities. Buenos Aires/Los Ángeles. 2015;

ARAUJO, Antonio. O processo colaborativo como modo de criação. in: Olhares ESCH/Revista da Escola Superior de Artes Célia Helena. n 1. 2009;

CABALLERO, Ileana Diéguez. Cenários liminares: teatralidades, performances e política. Uberlândia, EdUFU: 2011;

CONCILIO, Vicente. BadenBaden. Modelo de ação e encenação em processo com a peça didática de Bertolt Brecht. Vicente Concilio. São Paulo: ECA/USP, 2013;

DESGRANGES, Flávio. Pedagogia do teatro: provocação e dialogismo. São Paulo: Hucitec, 2006;

FABIÃO, Eleonora. Performance e Teatro: poéticas e políticas da cena contemporânea. In: Revista Sala Preta, Vol. 8. ECA/USP. São Paulo, 2008;

FERNANDES, Fernanda V. O personagem negro na literatura dramática francesa do século $X X$ : La putain respectueuse, de Jean-Paul Sartre, e Combat de nègre et de chiens, de Bernard-Marie Koltès. 2014. 234 f. Tese (Doutorado em estudos de Literatura) - Programa de Pós-Graduação em Letras, Universidade Federal do Rio Grande do Sul, Porto Alegre. 2014. FERNANDES, Fernanda Vieira. Poética, concepção e composição da escrita dramática no "Laboratório de dramaturgismo e direção rotativa". Grupo de Estudos em Teatro: Histórias e Dramaturgias. Pró-Reitoria de Pesquisa. UFPel. 2016;

FERNANDES, Sílvia. Performatividade e gênese da cena. In: Revista Brasileira de Estudos da Presença, Vol. 3, N.2. PPGEDU/UFRGS. Porto Alegre, 2013;

FISCHER, Estela. Processo colaborativo e experiências de companhias teatrais brasileiras. São Paulo: Hucitec, 2010;

FREITAS, Angélica. Um útero é do tamanho de um punho. São Paulo: Cosac \& Naif, 2013. GOLDBERG, RoseLee. A arte da performance do futurismo ao presente. São Paulo: Martins Fontes Editora, 2006;

KOLTÈS, Bernard-Marie. Combate de Negro e de Cães/O retorno ao Deserto/Tabataba. Trad. Angela Leite Lopes. São Paulo: Aliança Francesa, Instituto Totem Cultural e Imprensa oficial do estado, 2010. 
KOUDELA, Ingrid A encenação contemporânea como prática pedagógica. in:

Urdimento/Revista de Estudos Pós-Graduados em Artes Cênicas do PPGT/UDESC, Florianópolis, 2008;

KOUDELA, Ingrid. ALMEIDA Jr., José Simões (org.). Léxico de Pedagogia do Teatro - 1 ed. - São Paulo: Perspectiva: SP Escola de teatro, 2015;

LEHMANN, Hans-Thies Teatro pós-dramático, doze anos depois. Revista Brasileira de Estudos da Presença, Porto Alegre, 2013;

LEHMANN, Hans-Thies. Teatro pós-dramático e teatro político. In: Sala Preta: Revista do Departamento de Artes Cênicas: São Paulo, 2003;

NETTO, Maria Amélia Gimmler. Caminho de vivência poética e de ação político-educativa: Jogatina de cenas. Cadernos de resumos da VIII Jornada Latino-Americana de Estudos Teatrais, 2015;

NETTO, Maria Amélia Gimmler. Composição de Cenas e Condução de Grupo em Processo Colaborativo de Criação Teatral no "Laboratório de Dramaturgismo e Direção Rotativa". Grupo de Estudos e Pesquisas em Teatro, Educação e Práxis Social. Pró-Reitoria de Pesquisa. UFPel. 2016;

NETTO, Maria Amélia Gimmler. Criação poética e reflexão estética compartilhadas no jogo de aprendizagem. In: 14 Simpósio da International Brecht Society, 2013, Porto Alegre. Anais de comunicação 14 SIBS, 2013;

NETTO, Maria Amélia Gimmler; Jogatina é um jogo de cenas, um exercício de criação em teatro. In: VIII CONGRESSO ABRACE, 2014, Belo Horizonte. Anais de comunicação do VIII Congresso ABRACE, 2014;

NICOLETE, Adélia. Criação coletiva e processo colaborativo: algumas semelhanças e diferenças no trabalho dramatúrgico. Revista Sala Preta. São Paulo: 2002, v. 2.

PAVIS, Patrice. A encenação contemporânea: origens, tendências, perspectivas. São Paulo: Perspectiva, 2013.

PICON VALLIN, Béatrice. La création collective au Théâtre du Soleil. L'avant-scène théâtre, n 1284-1285 - pp. 86-97 - 1er juillet 2010. 